\title{
EDUCAÇÃO PERMANENTE, NÃO FORMAL, COMO INSTRUMENTO PARA A VALORIZAÇÃO E O RECONHECIMENTO DO IDOSO: O MODELO DA UNATI/UEM
}

\author{
PERMANENT EDUCATION, NO FORMAL, AS A TOOL FOR ELDERLY \\ APPRECIATION AND RECOGNITION: A MODEL OF UEM/UNATI
}

\author{
Eliane Rose Maio ${ }^{1}$ \\ Maria Carolina Gobbi dos Santos Lolli ${ }^{2}$
}

RESUMO: O aumento da população idosa é um fenômeno mundial. Tal situação despertou a necessidade do reconhecimento dessas pessoas. Com o intuito de valorizar e garantir a participação dos mais velhos na sociedade foram criadas as universidades abertas à terceira idade. Idealizadas pelo professor Vellas, essas instituições espalharam-se pelo mundo todo e chegaram ao Brasil na década de 1980. A Universidade Aberta da Terceira Idade, da Universidade Estadual de Maringá, criada em 2009 e guiada pelos princípios da educação permanente não formal, atualmente atende 400 alunos com idade igual ou superior a 60 anos de idade, ofertando 40 cursos gratuitos, divididos e organizados em seis eixos: "Arte e cultura", "Processos e procedimentos comunicativos", "Saúde física e mental", "Meio físico e social", "Direito e Cidadania" e "Humanidades". A grande procura por essas instituições pode ser explicada pelo fato de representarem a oportunidade da participação social em atividades compatíveis com as reais capacidades dos idosos, sem que estes sintam constrangimento ou vergonha por participar delas.

Palavras-chave: Idoso. Educação permanente. Educação não formal. Universidade Aberta à Terceira Idade.

\begin{abstract}
The increase in the elderly population is a worldwide phenomenon. That got the need to recognize these people, and the creation of specific institutions. In order to enhance and ensure the participation of older people in society, the universities open to seniors were created. Conceived by Professor Vellas, these institutions were dispersed throughout the world and arrived in Brazil in the 1980s. The University Open to Senior from Maringá's stadual university, created in 2009 and guided by the principles of permanent non-formal education, currently serves 400 students aged less than 60 years old, offering 40 divided and organized into six axes free courses: "Art and culture"; "Communicative processes and procedures"; "Physical and mental health", "physical and social Half"; "Law and Citizenship" and "Humanities". The high demand for these institutions can be explained because they represent the opportunity for social participation in consistent with the actual capacity of older people, without embarrassment or shame activities.
\end{abstract}

Keywords: Elderly. Permanent educacion. No formal education. University Open to Seniors.

Doutora em Educação. Universidade de Estadual de Maringá. E-mail: elianerosemaio@yahoo.com.br

2 Mestre em Educação. Diretora do Foco Atendimento em Educacional especializado. E-mail: profcarolinasantos@gmail.com 


\section{Introdução}

O envelhecimento da população é um fenômeno mundial, característico do século XX, e que a cada dia ocorre mais rapidamente. Esse fato, explicado pelo aumento da expectativa de vida, pode ser diretamente relacionado às melhorias na qualidade de vida e aos avanços da medicina e também da tecnologia (NOVAES, 2007, LOLLI, 2015).

No Brasil, da mesma forma, podemos perceber tal realidade e, portanto, fica clara a necessidade de discussão e estudo a respeito do tema. Para ilustrar tamanha importância, relatamos informações do censo realizado no ano de 2010, o qual informa que o número de idosos chegou a 20,6 milhões de pessoas, correspondendo a $10,8 \%$ da população mundial (IBGE, 2010). O mesmo documento descreve que nos próximos vinte anos a população com mais de 60 anos de idade deverá ultrapassar 30 milhões de pessoas.

Esse aumento progressivo do número de idosos nos remete a um grande e importante desafio social, cultural, econômico e político, que é o de incluir cada vez mais a pessoa idosa na sociedade, embora, conforme o pensamento de Salgado (1991), o mito presente é de que a velhice é uma etapa da vida totalmente negativa e improdutiva. Para Inouye (2008), políticas inclusivas, como forma de desmarginalizar as pessoas idosas, deverão ser incluídas nessa meta de transformação do perfil da sociedade contemporânea.

Para grande parte dos idosos, a idade causa diversas alterações no cotidiano, listadas, inclusive, por Pascual (2002), como: perda do status profissional, resultante da aposentadoria; insegurança e sensação de inutilidade; perda de energia pelo comprometimento de condições de saúde causado por doenças, exigindo mais e maiores cuidados médicos, despesas e atenção familiar; perdas familiares, afetivas e sociais que reduzem seus relacionamentos; falta de oportunidades sociais e de lazer; transformações físicas e hormonais e de tônus vital que trazem a necessidade da aquisição de novos hábitos de vida. Diante disso, Torres (2001) aponta como fundamental a garantia de assistência ao idoso visando seu bem-estar, sua autonomia, sua independência e inserção familiar e social para que ele consiga viver ativo, participativo e produtivo, além de ter saúde.

Foi atendendo a essa prerrogativa que a Organização Mundial da Saúde (OMS) adotou o termo 'envelhecimento ativo', no final dos anos 90, para expressar o processo de conquista dessas oportunidades. A expressão procura transmitir uma mensagem mais abrangente do que de fato é o 'envelhecimento saudável', e reconhecer, além dos cuidados com a saúde, outros fatores que afetam o modo como os indivíduos e as populações envelhecem (KALACHE e KICKBUSH, 1997).

\footnotetext{
O envelhecimento ativo aplica-se tanto a indivíduos quanto a grupos populacionais. Ele permite que as pessoas percebam o seu potencial para o bem-estar físico, social e mental ao longo do curso da vida, e permite que os idosos participem da sociedade de acordo com suas necessidades, desejos e capacidade. A palavra "ativo" refere-se à participação contínua nas questões sociais, econômicas, culturais, espirituais e civis, e não somente à capacidade de estar fisicamente ativo ou de fazer parte da força de trabalho. O objetivo do envelhecimento ativo é aumentar a expectativa de uma vida saudável e a qualidade de vida para todas as pessoas que estão envelhecendo, inclusive as que são frágeis, incapacitadas fisicamente, e que requerem cuidados (OMS, 2002, p.14).
}

Tudo isso despertou em várias nações a necessidade do reconhecimento da existência do idoso e a importância de destacar sua relevância social e as suas necessidades. Surgem, então, nessa prerrogativa, as primeiras iniciativas para a educação dos indivíduos mais velhos.

Diante desse argumento, cabe citar o conteúdo de um texto publicado por Moody, em 1976, que conceitua alguns modelos de educação para a velhice. O documento preconiza que tal educação deve ser um meio de manutenção das habilidades e das experiências dos idosos para que eles possam participar e interferir nos dilemas da sociedade por meio de programas educacionais 
específicos e ainda de acordo com a vontade deles, além de ser fundamentado na ideia de autorrealização e de educação permanente, com o reconhecimento dos valores, direitos e oportunidades dos idosos.

Esse desejo não é uma meta tão recente. Cachione (2012) descreve que depois da Segunda Guerra Mundial, em 1968, foram criadas as Universidades do Tempo Livre, idealizadas e construídas na França. Essas instituições tinham por finalidade, além da alfabetização de adultos, transmitir informações sobre saúde, religião, política e trabalho, com a intenção de ocupar o tempo livre dos aposentados e favorecer as relações sociais entre eles.

\section{Universidade Aberta à Terceira Idade: raízes históricas e significados}

No período pós-guerra, percebemos uma valorização das teorias humanistas e uma preocupação social que podem ser exemplificadas pela criação da Universidade de Ciências Sociais de Toulouse, a "Université du Troisième Âge (UTA)" - Universidade da Terceira Idade - por Pierre Vellas, especialista em Direito Institucional, em 1973 (CACHIONE, 2012).

Cachione (1999) explica que a verdadeira intenção do professor Vellas era abrir a universidade para todos os idosos, sem exceção, para oferecer-lhes atividades artísticas, intelectuais e físicas. Entretanto, conseguiu extrapolar esse desejo, alcançando o feito do programa 'Universidade da Terceira Idade' (UTI), que era ultrapassar as fronteiras da França com contribuições em pesquisas para a melhoria da qualidade de vida dos idosos, e com uma metodologia própria de estímulo para reflexões, consciência crítica e o exercício da cidadania.

Liberato (1996) e também Cachione (1999) descreveram que outras instituições no mundo também implantaram o Programa Universidade da Terceira Idade. Primeiro em 1975, na Polônia, houve a criação da Universidade da Terceira Idade de Varsóvia, e depois em Genebra, na Suíça, inaugurou-se a 'Fondation de l'Université du 3a Âge'. No mesmo ano, o programa se expandiu para universidades dos Estados Unidos, da Itália, da Espanha e do Canadá. Em 1976 foi a vez do Japão. No ano de 1977, a Áustria implantou a 'Associação Austríaca de Cursos Universitários', que organizou diversos cursos na área gerontológica em Viena, Gratz e Salsburg. O ano de 1979 foi marcado pela implantação do Programa por Universidades da Inglaterra, de Israel e de Jerusalém. A ex-União Soviética criou as Universidades de Saúde e de Longevidade; e a Alemanha, cursos para aposentados. Em 1987, na Suíça, mais precisamente na Universidade de Zurique, foi inaugurada a Universidade para Idosos (CACHIONE, 1999).

Por fim, na década de 80, essa ideia chegou à América Latina, começando pelo Uruguai, a Argentina, o México e, finalmente, o Brasil. Na América Latina, o programa é acessível para todos os idosos sem limite de idade e nível escolar, como apresenta Bayley (1994).

Em 1975, com o reconhecimento e a expansão mundial do projeto proposto por Pierre Vellas, foi fundada a "Association Internationale des Universitès du Troisième Âge" - Aiuta. Essa associação integra instituições universitárias de todas as partes do mundo, as quais têm o mesmo objetivo de contribuir para a melhoria das condições de vida dos idosos (SWINDELL E THOMPSON, 1995). Salientamos que no ano de 1981 já existiam mais de 170 instituições associadas à Aiuta, e no ano de 1999, mais de 5 mil instituições, conforme descrevem os estudos de Cachione (2012).

Fundamentadas no diálogo igualitário, na inteligência cultural, na capacitação para mudanças e na solidariedade, as universidades sobre as quais aqui falamos são consideradas modelos de atenção à pessoa idosa, pois se baseiam na diversidade e na equidade e têm como premissa básica o fato de todos terem o mesmo direito de pensar, de aprender o que desejam e necessitam, buscando uma melhoria em sua qualidade de vida (MARTUCCI; PURQUÉRIO, 2005).

Acreditamos que essas instituições, difundidas em todos os continentes, têm oferecido meIhores condições de cuidado para pessoas com mais de 60 anos de idade, com equilíbrio, autonomia e produtividade, assim como têm garantido seus valores éticos, políticos, sociais e culturais. Proposições que vão muito além das primeiras desse tipo de instituição que, como já dito anteriormente, 
eram a simples busca de preenchimento do 'ócio' ou ainda de ocupar o tempo vago dessas pessoas.

Nas palavras de Paz (2006), envelhecer dignamente é direito de todos, sem limite de idade, bem como ser respeitado e não ser tratado como descartável pelo tempo. O autor reconhece que a legislação brasileira possibilita um grande avanço social, já que não garante apenas o direito dos idosos, mas também a educação das novas gerações para que estejam preparadas para entender o processo do envelhecimento.

No Brasil, devemos fazer menção ao artigo 25 do Estatuto do Idoso (BRASIL, 2003), que contempla, além do incentivo à produção de materiais como livros e periódicos com conteúdo pertinente ao idoso, a criação de Universidades Abertas à Terceira Idade.

Apesar disso, Palma (2000) relata que pode soar um pouco estranho aos ouvidos de algumas pessoas o tema "educação para idosos". Esse estranhamento pode ser entendido pela ideia, ainda dominante na nossa cultura, de que "educação" e "velhice" são termos incompatíveis e que os idosos já estariam fora do processo de aprendizagem, como se para alguém aprender algo existisse uma data estabelecida e um ritmo previamente demarcado.

Sabemos, graças à neurociência, que a capacidade de aprender quando a pessoa está em idade mais avançada não é igual à capacidade de aprender na juventude, mas devemos aceitar a ideia de que os idosos continuam aprendendo de outra forma, com outro ritmo, com outros interesses particulares (DEL PRETTE; DEL PRETTE, 2002).

\begin{abstract}
Baseados nas modificações intelectuais que podem ocorrer com o envelhecimento, especialmente em relação à memória, tem-se a falsa ideia de que há uma completa deterioração das funções cognitivas, perdendo, assim, o idoso a sua capacidade de aprendizagem. Este preconceito tem suas raízes também numa visão ainda hoje deturpada da educação que se destina aos jovens com o objetivo de prepará-los para competir no mercado de trabalho, isto é, para produzir. Por isso, parece tão estranho a figura do idoso ocupando um lugar nas salas de aula, nas oficinas, disputando vagas nas universidades e até mesmo no mercado de trabalho (LOURES et al., 2007, p. 197).
\end{abstract}

Reafirmamos diante do exposto que a educação tem se constituído, mais do que nunca, em um elemento significativo também para as pessoas idosas, já que ela tem um papel transformador importantíssimo.

Falando um pouco da realidade das Universidades Abertas à Terceira Idade do Brasil, devemos referenciar o pioneirismo do Serviço Social do Comércio (Sesc) com os primeiros 'Grupos de Convivência' e, posteriormente, com as primeiras Escolas Abertas para a Terceira Idade, como explica Cachione (2012, p.3).

\footnotetext{
Nas décadas de 1960 e 1970, foram criados os primeiros programas com cunho educativo para os mais velhos. O SESC liderou este trabalho, que posteriormente, com a internacionalização da gerontologia, encontrou solo fértil nas universidades brasileiras. Nesse mesmo período, importamos e incorporamos a expressão terceira idade, presença predominante na denominação de grupos, centros e programas nacionais para pessoas idosas.
}

Em 1982, foi fundado na Universidade Federal de Santa Catarina o Núcleo de Estudos da Terceira Idade (Neti), que implementou a realização de estudos e a divulgação de conhecimentos gerontológicos (CACHIONE, 2012).

Os estudos de Cavalcante (1989) apontam que, no ano de 1988, foi fundada pela Universidade Estadual do Ceará a Universidade Sem Fronteiras, que propôs várias atividades de extensão, como: a formação de grupos de pessoas idosas, apoio docente e cursos especiais para idosos, além de cursos e seminários sobre envelhecimento. Ainda no final da década de 80, Veras e Camargo 
(1995) atestam a criação do Núcleo de Assistência do Idoso na Universidade Estadual do Rio de Janeiro.

Em 1990, a Pontifícia Universidade Católica de Campinas (PUC/Campinas) instituiu a Universidade Aberta à Terceira Idade (Unati). Esse programa marcou a evolução da gerontologia educacional no Brasil e foi ainda responsável pela pulverização de programas voltados para idosos em vários estados brasileiros, como São Paulo, Pará, Rio de Janeiro, Ceará, Pernambuco, Goiás, Maranhão, Rio Grande do Sul, Distrito Federal e Paraná (CACHIONE, 2002, LACERDA, 2009). Outra informação importante sobre a Unati da PUC/Campinas é o fato de ter sido o primeiro programa na mídia em caráter nacional, possibilitando um grande incremento de instituições congêneres em todo o país (LACERDA, 2009).

No Brasil, as Unati podem ser encontradas com variadas denominações:

Universidade Aberta à Terceira Idade; Universidade para a Terceira Idade; Universidade com a Terceira Idade; Universidade na idade Adulta; Universidade Alternativa; Universidade sem Limites; Universidade sem Fronteiras; Programa da Terceira Idade; Faculdade da Terceira Idade; Faculdade de Atuação Permanente; Núcleo de Estudo e Pesquisa ou Núcleo Integrado de Apoio a Terceira Idade; Centro Regional de Estudos e Atividades da Terceira Idade; Centro de Extensão em Atenção à Terceira Idade; Programa de Participação Permanente; Projeto Sênior; Atividade Física para a Terceira Idade; Curso de Extensão para a Terceira Idade; Grupo de Convivência; Grupo de Trabalho da Terceira Idade; Encontros para a Terceira Idade; Educação Continuada e Terceira Idade (CACHIONI, 2003, p.52).

Segundo Taam (2009), as Unati não se diferenciam somente em suas denominações, mas também em outros pontos, como: horários, formas de ingresso, pré-requisitos para participação, atividades, cursos oferecidos e organizações, mas todas, de maneiras diferentes, "[...] contribuem para que o idoso seja autor e ator principal de sua própria vida" (TAAM, 2009, p. 46).

Além disso, todos esses programas compartilham de propósitos

como o de rever os estereótipos e preconceitos com relação à velhice; promover a autoestima e o resgate da cidadania; incentivar a autonomia, a integração social e a autoexpressão, e promover uma velhice bem-sucedida em indivíduos e grupos. Essas instituições hoje se espalham por todo o país (CACHIONI, 2012, p. 38).

Assim, compreendemos que as propostas estão voltadas para direcionar maior atenção à qualidade de vida, à promoção da saúde, à manutenção da autonomia e à inserção social dos idosos. Da mesma forma, é preciso mencionar a oferta de mais oportunidades educacionais e culturais que possibilitem e promovam o desenvolvimento pessoal e coletivo dessas pessoas.

No ano de 2009, nosso país contava com 100 Universidades Abertas à Terceira Idade. Atualmente, existem 156 unidades espalhadas pelo Brasil (LOLLI, 2015). Especificamente no estado do Paraná, o programa é desenvolvido na Universidade Estadual do Centro-Oeste do Paraná (Unicentro), nos campi Irati e Santa Cruz, em Guarapuava; na Universidade Estadual de Ponta Grossa (UEPG) e na Universidade Estadual de Maringá (UEM) (TAAM, 2012).

\section{Um pouco sobre a Unati/UEM}

A Universidade Estadual de Maringá, preocupada com os idosos da região, antes mesmo da criação da sua Universidade Aberta à Terceira Idade (Unati/UEM), esboçou um pré-projeto de atendimento a essa parcela da população oferecendo cursos nas áreas de educação para a saúde, arte e 
cultura, conhecimentos sobre a terceira idade, línguas estrangeiras, informática e atividades físicas.

Os autores Stieltjes e Taam (2011) descrevem que a Unati/UEM foi oficialmente designada em 14 de dezembro de 2009. Já a aula inaugural aconteceu no dia 7 de março do ano de 2010. Na ocasião foram oferecidas 340 vagas em 54 cursos ou atividades diferentes nas áreas já citadas anteriormente, incluindo ainda oficinas de teatro e atividades como dança e hidroginástica, as quais foram ministradas por 44 professores efetivos da Universidade Estadual de Maringá.

Atualmente, a Unati/UEM atende 400 alunos com idade igual ou superior a 60 anos de idade, ofertando 40 cursos gratuitos, divididos e organizados em seis eixos temáticos, a saber: "Arte e cultura", "Processos e procedimentos comunicativos", "Saúde física e mental", "Meio físico e social"; "Direito e Cidadania" e "Humanidades".

Os cursos são oferecidos em quatro dias da semana, nos turnos da manhã e da tarde; a carga horária varia de acordo com a natureza do curso e o conteúdo programático: $17 \mathrm{~h}, 34 \mathrm{~h}, 68 \mathrm{~h}$ ou $102 \mathrm{~h}$. As aulas são ministradas por professores da UEM e computadas em suas atribuições de ensino. As sextas feiras são reservadas para palestras, minicursos, reunião de grupos de pesquisa, etc. [...] 0 aluno da UNATI escolhe os cursos que deseja fazer (não ultrapassando o limite de quatro cursos por semestre). O número de vagas é definido pelo docente responsável pelo curso (STIELTJES; TAAM, 2011. p.151).

Os cursos não têm cunho profissionalizante, então os alunos têm liberdade para escolher as atividades de acordo com suas preferências. Além disso, todo o material necessário como livros, textos, materiais de pintura e desenho, entre outros, é disponibilizado gratuitamente, conforme relatam Stieltjes e Taam (2011).

No dia 29 de julho do ano de 2013, a Unati/UEM começou a funcionar também no campus regional da Universidade Estadual de Maringá, em Cianorte (UEM/CRC), ofertando 50 vagas para pessoas com mais de 60 anos de idade em nove cursos: "Informática básica", "Inglês", "Espanhol", "Educação financeira e economia doméstica", "Introdução ao mundo do vinho", "O direito e a terceira idade", "Introdução às redes sociais", "Curso básico de fotografia" e "Desenho e pintura".Vale citar que as turmas da Unati/UEM são marcadas pela diversidade de nível de escolaridade, nível socioeconômico, de idade, de experiências de vida, de capacidades fisiológicas e condições físicas, e de hábitos diários. Fazendo uso das palavras de Stieltjes e Taam (2011), na Unati/UEM existe subjetividade. Os autores complementam que os alunos são bastante críticos em relação aos ensinamentos recebidos, estão sempre perguntando e comentando. Essa interação proporciona uma compreensão entre alunos e professores não apenas em relação aos conteúdos das disciplinas, "mas em relação à sua realidade complexa, surpreendente, desconcertante, sempre desafiadora" (STIELTJES; TAAM, 2011. p.154).

Sonhamos a UNATI que queríamos, lutamos por ela e fizemos do nosso sonho o sonho de muitos companheiros da academia [...] a UNATI/UEM passa a fazer parte da vida da universidade, apresentando-se como educação permanente. [...] Professores e coordenadores sabem que atuam com pessoas que trazem marcas de uma longa existência, onde valores e crenças foram construídos e algumas vezes destruídos (STIELTJES; TAAM, 2011, p.151).

Desse modo, defendendo a ideia de que nunca é tarde para aprender, a Unati/UEM proporciona a oportunidade para que os idosos possam redescobrir formas de viver adequando sua metodologia de ensino e conteúdos e integrando diferentes campos do saber. 


\section{Educação permanente para a terceira idade}

O termo "Educação Permanente" foi idealizado em 1972, pela Unesco, no Relatório "Aprender a Ser" (FAURE, 1972). O Relatório Faure (1972), como também é denominado, lançou as bases da "educação ao longo de toda a vida", ampliando a compreensão da educação formal tradicionalmente conhecida e apresentando conceitos de educação global (dentro e fora da escola) e educação permanente ao longo de toda a existência. Ele parte do princípio de que

uma educação para formar o homem completo, cujo advento se torna mais necessário à medida que coações sempre mais duras separam e atomizam cada ser, terá de ser global e permanente. Trata-se de não mais adquirir, de maneira exata, conhecimentos definitivos, mas de se preparar para elaborar, ao longo de toda a vida, um saber em constante evolução e de "aprender a ser" (FAURE, 1972, p. 10).

A educação ganha então uma concepção nova, sendo reconhecida a premissa de que o indivíduo pode também aprender com as experiências acumuladas. Assim, a educação

[...] tem lugar em todas as idades da vida e na multiplicidade de situações e das circunstâncias da existência. Retoma a verdadeira natureza, que é ser global e permanente, e ultrapassa os limites das instituições, dos programas e dos métodos que lhe impuseram ao longo dos séculos (FAURE, 1972, p. 225).

Seguindo essa ideia, a Comissão Internacional sobre Educação para o Século XXI, sob a coordenação de Jacques Delors (1998), "Educação um tesouro a descobrir", proposta pela Unesco, também considera essa forma de educação com a perspectiva da educação permanente mais ampla e atual. Isto é justificado pelo fato de a educação ocupar cada vez mais espaço na vida das pessoas, o que é explicado pela evolução do mundo e da sociedade, exigindo uma atualização contínua dos conhecimentos, visto que "uns saberes penetram e enriquecem os outros" (DELORS, 1999, p. 104).

A educação permanente divulgada no texto tem como princípio

fazer com que cada indivíduo saiba conduzir seu destino [...] a educação ao longo de toda a vida torna-se assim, para nós, o meio de chegar a um equilíbrio mais perfeito entre trabalho e aprendizagem bem como ao exercício de uma cidadania ativa (DELORS, 1999, p. 105).

Nessa perspectiva de educação permanente, unida ao fato de a universidade ser o espaço da busca por conhecimentos, pesquisa e democratização do saber, é que defendemos a ideia do ambiente universitário também ter espaço para o idoso. No momento em que ele se insere na comunidade acadêmica, acontece a interação entre gerações diferentes, fomentando debates sobre questões relativas ao envelhecimento e demonstrando que preconceito e discriminação, sustentados socialmente e culturalmente, não possuem nenhuma fundamentação científica.

\section{Considerações finais}

Entendemos que a educação permanente, não formal, é um instrumento bastante eficiente para a valorização e para o reconhecimento do idoso como pessoa participativa. Tal fato pode ser evidenciado no trabalho desenvolvido na Unati/UEM, com a aceitação e a procura sempre crescente pelos serviços oferecidos pela referida instituição.

Diante disso, afirmamos que é necessária a elaboração de um projeto de currículo específico para as pessoas idosas, contemplando atividades que estimulem prioritariamente a sua autonomia, 
aspectos cognitivos, responsabilidade social e integração na sociedade, considerando para isso a sua experiência, sua realidade, suas limitações e seus interesses, como atualmente é realizado na Universidade Estadual de Maringá. No entanto, alertamos sobre a necessidade de haver professores preparados para ouvir, entender e responder as perguntas dos idosos sem receio, ponderando ainda o fato de estes possuírem uma vasta experiência de vida e de serem adultos e não crianças. Vale ressaltar que as pessoas idosas não devem ser tratadas com diferença, como se fossem crianças, muito menos com piedade. Eles precisam de respeito e, mais ainda, precisam de que seus direitos sejam garantidos.

A grande procura pela Universidade Aberta à Terceira Idade da Universidade Estadual de Maringá por idosos pode ser explicada pelo fato de a instituição representar uma nova oportunidade para sua participação social em atividades compatíveis com suas reais capacidades, sem constrangimento ou vergonha, o que possibilita a essas pessoas a chance de conviverem com outros indivíduos mais jovens no mesmo espaço, a universidade. Essa convivência, a nosso ver, é benéfica para todos os envolvidos, já que os mais jovens podem aprender a enxergar os mais velhos como pessoas ativas, produtivas e participativas, e os mais velhos podem ensinar muito de suas experiências e valores morais, como o respeito, para os mais jovens. Tal afirmação pode ser constatada pela preocupação da referida instituição não só com a educabilidade dos idosos, mas também com a oferta de oportunidades variadas de atividades que promovam interações sociais, convivência com professores e com discentes de outras idades e outros cursos, além do estímulo a pensar, fazer, aprender e integrar.

Desse modo, defendemos a ideia de que nunca é tarde para aprender, desde que sejam oferecidos métodos de ensino adequados, conteúdos de interesse nos quais haja a garantia da transdisciplinaridade e professores preparados. Assim, integrando diferentes campos do saber, aumentamos a possibilidade de os idosos redescobrirem novas formas de viver mais e melhor.

\section{Referências}

BAYLEY, A. UTOPÍA Y EDUCATIÓN. UNI3: El Derecho a Ser. Documento. Montevideo, Uruguai. 1994.

BRASIL. Estatuto do Idoso. Coord. André Arruda. Rio de Janeiro: Roma Victor, 2003.

CACHIONE, M. Universidades da Terceira Idade: Das origens à experiência brasileira. In: NERI, A. L. e DEBERT, G. G. (Orgs.). Velhice e Sociedade. Papirus. Campinas. 1999, p.141-178.

CACHIONE, M. Quem educa os idosos? Um estudo sobre professores de universidades da terceira idade. Campinas: Alínea, 2003.

CACHIONE, M. Universidade da Terceira Idade: história e pesquisa. Kairós. Revista da Faculdade de Ciências Humanas e Saúde. V. 15, n. 7, p.99-115, 2012.

CAVAlCANTE, A. M. Maturidade: Tempo e Vida. Fortaleza: Universidade Estadual do Ceará. 1989.

DEL PRETTE, Z.; DEL PRETTE, A. Psicologia das habilidades sociais: terapia e educação. Petrópolis/RJ: Vozes, 2002.

DELORS, J. Educação: um tesouro a descobrir. Relatório para a UNESCO da Comissão Internacional sobre Educação para o Século XXI. (7’a ed.). São Paulo (SP): Cortez. 1998.

IBGE - Instituto Brasileiro de Geografia e Estatística. Censo demográfico de 2000 e 2005.

IBGE - Instituto Brasileiro de Geografia e Estatística. Censo demográfico de 2010.

INOUYE, K. Educação, qualidade de vida e Doença de Alzheimer: visões de idosos e seus familiares. Dissertação 
de Mestrado, Centro de Educação e Ciências Humanas, Universidade Federal de São Carlos, São Carlos. 2008.

FAURE, Edgar. Aprender a ser. Livraria Bertrand/Difusão Europeia do Livro, São Paulo, 1972.

KALACHE, A. KICKBUSCH, I. A global strategy for healthy ageing. World Health. v.4, p. 4-5, 1997.

LACERDA, S. M. Universidade aberta à terceira idade: representações da velhice. Dissertação (Mestrado). Pontifícia Universidade Católica de São Paulo, São Paulo, 2009.

LOLLI, M.C.G.S. Quebrando o Silêncio: Uma análise das representações de idosos(as) sobre educação sexual e sexualidade no envelhecimento. Dissertação de Mestrado. Programa de Pós-Graduação em Educação. Universidade Estadual de Maringá, Maringá, 2015.

MARTINS DE SÁ, J. Fundamentos da Universidade Aberta: cidadania, educação continuada e convivência. Aula Inaugural da Unati/UCG, 14 set. 1992.

MARTUCCI, E.M.; PURQUÉRIO, M.C.V. Universidade Aberta da terceira idade: projeto pedagógico, 2005. Disponível em: < http://www.fesc.saocarlos.sp.gov.br/arquivos/pdfs/Microsoft\%20-\%20Projeto\%20Pedagogico\%20 UATI.pdf>.

MOODY, R. H. Philosophical presuppositions of education for old age. Educational Gerontology, v.1, n.1. 1976.

NOVAES, M.R.C.G. Assistência farmacêutica ao idoso - uma abordagem multiprofissional. Brasília: Thesaurus, 2007.

ORGANIZAÇÃO MUNDIAL DA SAÚDE (OMS) (2002). Envelhecimento ativo: uma política de saúde / World Health Organization. (Trad. S, Gontijo.), Brasília: Organização Pan-Americana da Saúde. 60p. 2002

PALMA, L. T. S. Educação permanente e qualidade de vida: indicativos para velhice bem sucedida. Passo Fundo: Ed. da UPF, 2000.

PASCUAL, C. P. A sexualidade do idoso vista com novo olhar. Tradução: Alda da Anunciação Machado. São Paulo: Loyola, 2002.

PAZ, S. F. Movimentos sociais: participação dos idosos. In: PY, L. et.al. Tempo de envelhecer: percursos e dimensões psicossociais. 2. ed. Holambra: Setembro, 2006, p. 229-256.

SALGADO, M. Velhice, uma nova questão social. São Paulo: Sesc, 1991.

SANTANA, R. F.; SANTOS, I. Para entender o envelhecimento. In: FIGUEIREDO, N. M. A.; TONINI, T. Gerontologia atuação da Enfermagem no processo do envelhecimento. 2a Ed. São Paulo: Yendis, 2012, p. 17-49.

SWINDELL, R.; THOMPSON, J. An International Perspective on the University of the Third Age. Educational Gerontology, v.21, n.5, p. 429-447. 1995. cross $^{\text {ref }}$ http://dx.doi.org/10.1080/0360127950210505

STIELTJES, C.; TAAM, R. A UNATI da UEM: educação e política. In: OLIVEIRA, Rita de Cássia da Silva; D’ALENCAR, Raimunda Silva (Orgs.). As experiências de universidades abertas em um Brasil que envelhece. 1. ed. Curitiba: CRV, 2011, p. 141 - 159.

TAAM, Regina. A educação não formal do Idoso em universidades da Terceira Idade e Centros de convivência. In: PARK, M. B., GROPPO, L.A. (Orgs.). Educação e Velhice. Holambra/SP: Setembro, 2009, p.39-49.

TAAM, Regina. A UNATI na RENAD: A inclusão das Universidades Abertas à Terceira Idade na Rede Nacional de Atenção ao Direito do idoso. Cadernos de Pesquisa Pensamentos Educacional, Universidade Tuiuti, 2012. 
TORRES, V. L. Velhice numa cidade do trópico. Dissertação. Escola de Enfermagem Anna Nery, Universidade Federal do Rio de Janeiro, Rio de Janeiro. 2001.

VELLAS, P. As oportunidades da terceira idade. Tradução de Claudio Stieljes e Regina Taam. Maringá (PR): Eduem; 2009.

VERAS, R. P. e CAMARGO JR, K. R. Idosos e universidade: parceria para a qualidade de vida. In: VERAS, R.P. (Org.) Terceira Idade: um envelhecimento digno para o cidadão do futuro. Rio de Janeiro: Dumará. 1995, p.11-27.

Recebido em setembro de 2014. Aprovado em outubro de 2015. 